\title{
Lymphocyte recovery after fingolimod discontinuation in patients with MS
}

Sara Nagy, MD, Msc, Jens Kuhle, MD, PhD, and Tobias Derfuss, MD

Neurol Neuroimmunol Neuroinflamm 2020;7:e874. doi:10.1212/NXI.0000000000000874

Correspondence

Dr. Nagy

sara.nagy@usb.ch

\section{Abstract}

\section{Objective}

To investigate the dynamics of immune cells recovery after treatment discontinuation of fingolimod in real-life clinical practice, we analyzed the course of lymphocyte reconstitution and its potential influencing factors in patients with multiple sclerosis (MS).

\section{Methods}

We analyzed leukocyte, lymphocyte, and granulocyte counts of 58 patients at 3, 6, and 12 months after fingolimod cessation and the following parameters as potential risk factors for a prolonged lymphopenia up to 12 months: age; sex; Expanded Disability Status Scale, and disease duration at the time of fingolimod start; type and number of previous immunomodulatory treatments; fingolimod treatment duration; lymphocyte count at baseline before fingolimod, at fingolimod stop, and at the time of therapy switch; time interval between fingolimod cessation and new treatment initiation; type of the follow-up immunomodulatory treatment; and corticosteroid administration after fingolimod cessation.

\section{Results}

All patients showed a drop of the lymphocyte count under fingolimod with no relevant leukopenia or neutropenia. One year after discontinuation, still $22 \%$ of the patients were lymphopenic and $54 \%$ of them did not reach $80 \%$ of the baseline lymphocyte value. Low lymphocyte counts before fingolimod start, under fingolimod, and at therapy switch, successive treatment with rituximab, and pretreatment with mitoxantrone were significantly associated with a prolonged immune cell recovery.

\section{Conclusions}

Prolonged lymphopenia after fingolimod cessation exists in a subgroup of patients with MS and should be considered in clinical practice, particularly when changing treatment regimens.

From the Department of Neurology (S.N., J.K., T.D.), University Hospital Basel, University of Basel; Division of Developmental- and Neuropaediatrics (S.N.), University Children's Hospital of Basel (UKBB), University of Basel; and Department of Biomedicine (I.K., T.D.), University Hospital Basel, Switzerland. 


\section{Glossary}

EDSS $=$ Expanded Disability Status Scale.

Fingolimod, a functional antagonist of sphingosine 1-phosphate receptor, effectively reduces long-term clinical and subclinical disease activity of MS by preventing the egression of lymphocytes from lymph nodes, resulting in a reduced lymphocyte count in the peripheral blood. ${ }^{1,2}$
Despite its efficacy and good tolerability, fingolimod is discontinued by $29 \%$ of patients after 2 years treatment duration. ${ }^{3}$ Most of these patients require a subsequent diseasemodifying treatment; however, the treatment-free period must be defined on an individual basis. Disease reactivation

Table 1 Baseline characteristics of all patients and of patients with normalized lymphocytes and prolonged lymphopenia 1 year after discontinuation of fingolimod

\begin{tabular}{|c|c|c|c|}
\hline Patient characteristics & $\begin{array}{l}\text { All } \\
\text { patients }\end{array}$ & $\begin{array}{l}\text { Patients with persistent lymphopenia } \\
\text { after } 1 \mathrm{y}(\mathrm{n}=11)\end{array}$ & $\begin{array}{l}\text { Patients with recovered lymphocytes } \\
\text { after } 1 \text { y }(n=38)\end{array}$ \\
\hline \multicolumn{4}{|l|}{ Age (y) } \\
\hline Mean $^{a}$ & $\begin{array}{l}38.3 \pm \\
12.1\end{array}$ & $40.9 \pm 10.2$ & $39.3 \pm 12.8$ \\
\hline Female, $n(\%)$ & $40(69)$ & $8(72.7)$ & $26(68.4)$ \\
\hline \multicolumn{4}{|l|}{$\begin{array}{l}\text { Time from first symptoms to } \\
\text { fingolimod start (y) }\end{array}$} \\
\hline Mean & $9.6 \pm 8$ & $8.8 \pm 4.2$ & $10.9 \pm 9.1$ \\
\hline \multicolumn{4}{|l|}{ EDSS at fingolimod start ${ }^{\mathrm{b}}$} \\
\hline Median (range) & $3(0-7)$ & $3(1.5-6.5)$ & $3(0-7)$ \\
\hline \multicolumn{4}{|l|}{ Fingolimod treatment duration (mo) } \\
\hline Mean & $\begin{array}{l}26.4 \pm \\
17.6\end{array}$ & $33.9 \pm 17.7$ & $24.7 \pm 18.7$ \\
\hline \multicolumn{4}{|l|}{$\begin{array}{l}\text { Duration of treatment break after fingolimod } \\
\text { discontinuation (d) }\end{array}$} \\
\hline Mean & $\begin{array}{l}75.8 \pm \\
80.1\end{array}$ & $74.3 \pm 97.7$ & $67.6 \pm 67.6$ \\
\hline \multicolumn{4}{|l|}{ Previous DMT, $\mathbf{n}$} \\
\hline Median (range) & $1(0-4)$ & $2(0-3)$ & $1(0-4)$ \\
\hline Patients with mitoxantrone, $\mathrm{n}$ & $4(6.9 \%)$ & $3(27.2 \%)$ & $1(2.7 \%)$ \\
\hline Patients with rituximab follow-up, $n$ & $18(31 \%)$ & $8(72.7 \%)$ & $10(26.3 \%)$ \\
\hline Patients without DMT after 1 y (\%) & $13(22.4)$ & $1(9 \%)$ & $12(31.6 \%)$ \\
\hline Patients restarting fingolimod within 1 y (\%) & $6(10.3)$ & n.a. & n.a. \\
\hline \multicolumn{4}{|l|}{ Lymphocyte count at baseline $\left(\times 10^{9} / \mathrm{L}\right)$} \\
\hline Mean & & $1.33 \pm 0.5$ & $2.18 \pm 1.13$ \\
\hline \multicolumn{4}{|l|}{ Lymphocyte count at fingolimod stop $\left(\times 10^{9} / L\right)$} \\
\hline Mean & & $0.30 \pm 0.06$ & $0.46 \pm 0.17$ \\
\hline \multicolumn{4}{|l|}{ Lymphocyte count at therapy switch $\left(\times 10^{9} / \mathrm{L}\right)$} \\
\hline Mean & & $0.68 \pm 0.13$ & $1.16 \pm 0.32$ \\
\hline
\end{tabular}

Abbreviations: DMT = disease-modifying treatment; EDSS = Expanded Disability Status Scale; n.a. = not applicable.

a Plus-minus values are means \pm SD.

${ }^{\mathrm{b}}$ The Expanded Disability Status Scale (EDSS) ranges from 0 to 10, with higher scores indicating greater disability. EDSS at baseline was not available in 2 patients. Patients with lymphopenia because of a follow-up treatment with alemtuzumab $(n=1)$ or restarting fingolimod $(n=6)$ were excluded. 
A

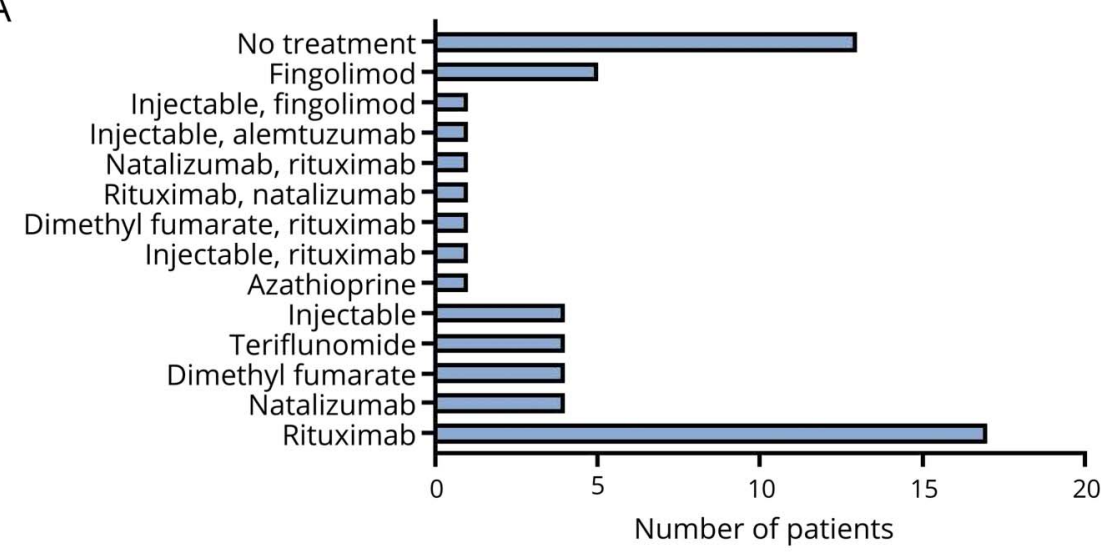

B

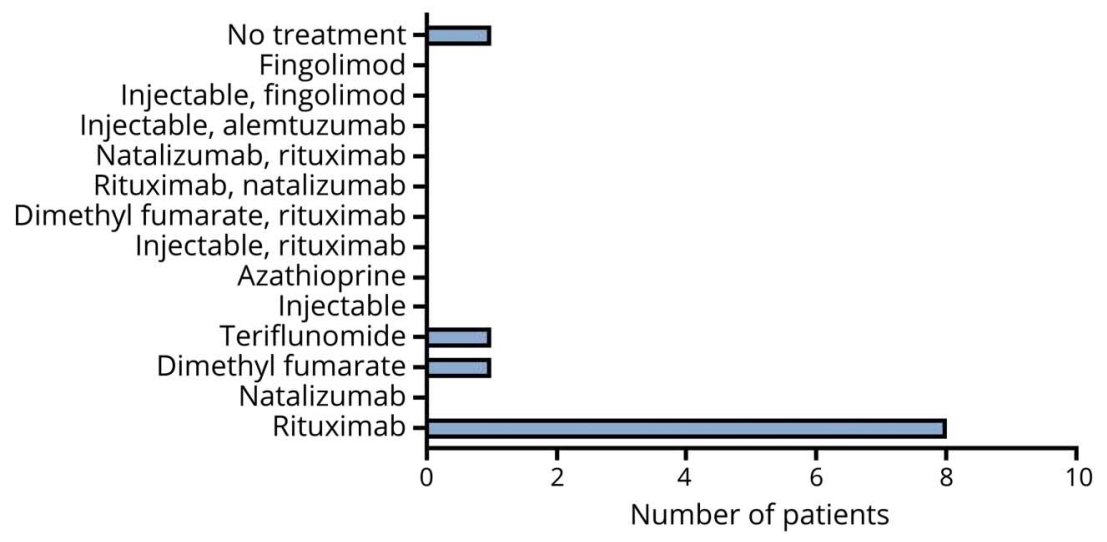

From all patients who stopped fingolimod, 13 received no further treatment, 6 restarted fingolimod, whereas the remaining patients were switched at least once to another disease-modifying treatment within the first year (A). Eleven patients remained lymphopenic even 12 months after fingolimod cessation, from whom 8 received rituximab as the follow-up treatment (B). Injectables: interferon beta-1a, interferon beta 1-b, or glatiramer acetate.

and rebound are potential risks in patients stopping fingolimod ${ }^{4}$; therefore, a long treatment break should be avoided. On the other hand, a rapid therapy switch without considering lymphocyte recovery could be associated with an increased risk of infections. Hence, knowledge of the lymphocyte recovery time and factors influencing it play a crucial role in the management of patients with MS who stop fingolimod. In clinical studies, lymphocyte count has been described to recover to $80 \%$ of baseline value by 3 months ${ }^{2}$; however, less is known about the duration of lymphopenia in real-life clinical practice. We aimed to analyze the course of lymphocyte recovery and potential influencing factors in the first year after fingolimod discontinuation in patients with MS.

\section{Methods}

Data of all patients with MS ( $\mathrm{n}=58)$ who stopped fingolimod treatment and participated in the Swiss MS Cohort-Study ${ }^{5}$ in our center were analyzed retrospectively. Only patients receiving fingolimod for at least 1 month and having available blood tests within 1 year after fingolimod cessation were included. Leukocyte, lymphocyte, and granulocyte counts were analyzed at 3, 6, and 12 months after fingolimod cessation. Lymphopenia was defined as $\leq 0.9 \times 10^{9} / \mathrm{L}$, leukopenia as $\leq 3.5$ $\times 10^{9} / \mathrm{L}$, and neutropenia as $\leq 1.3 \times 10^{9} / \mathrm{L}$. Lymphopenia was further divided into 3 groups: grade $1\left(0.8-0.899 \times 10^{9} / \mathrm{L}\right)$, grade $2\left(0.5-0.799 \times 10^{9} / \mathrm{L}\right)$, and grade $3\left(<0.5 \times 10^{9} / \mathrm{L}\right)$. The following parameters were analyzed for their relation to prolonged lymphopenia: age, sex, Expanded Disability Status Scale (EDSS), and disease duration of the patients at the time of fingolimod start; type and number of previous immunomodulatory regimens; fingolimod treatment duration; time interval between fingolimod cessation and new treatment initiation (in case of therapy switch); lymphocyte count before fingolimod, at fingolimod stop, and at the start of a subsequent treatment; the type of follow-up immunomodulatory treatment after fingolimod cessation; and corticosteroid administration because of relapses after therapy switch.

The association between potential risk factors and lymphocyte count at 12 months was assessed using a simple linear model. Thereafter, significant predictors were adjusted for other covariates in a multiple univariate model because of the small patient number.

\section{Standard protocol approvals, registrations, and patient consents}

All patients signed an informed consent and agreed to an anonymous data analysis. The study was approved by the local ethics committee (ID: 2019-02014). 
Figure 2 Lymphocyte recovery after discontinuation of fingolimod

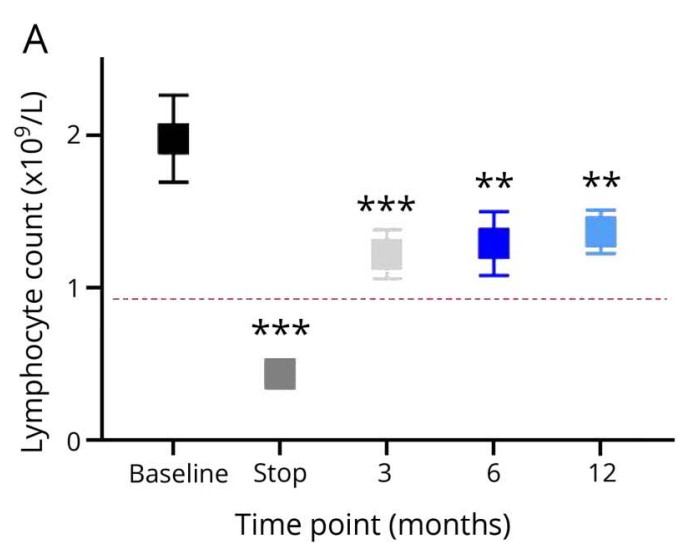

B

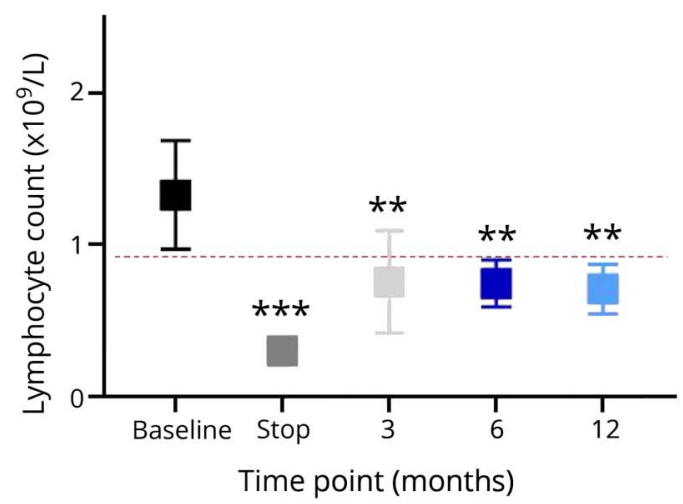

Mean lymphocyte counts $\left(\times 10^{9} / \mathrm{L}\right)$ are represented at baseline (black), fingolimod stop (dark gray), and at 3 (light gray), 6 (dark blue), and 12 months (light blue) after fingolimod discontinuation in the total study population (A) and in the patient group with prolonged lymphopenia (B). Corresponding tables represent mean lymphocyte counts $\left(\times 10^{9} / \mathrm{L}\right), 95 \%$ confidence intervals in [] and patient numbers ( $n)$. Red dotted lines represent lower limit of lymphocytes $\left(0.9 \times 10^{9} / \mathrm{L}\right)$. Significance level $* \star p<0.001, * \star \star p<0.0001$.

\section{Data availability}

Anonymous data will be shared upon request from any qualified investigator.

\section{Results}

\section{Baseline characteristics}

Fifty-six patients with relapsing-remitting $M S$ and 2 with primary progressive MS were included (Supplemental figure 1, links.lww.com/NXI/A305). Treatment discontinuation reasons included adverse events $(n=17,29.3 \%)$, disease activity $(n=15,25.9 \%)$, secondary progression $(n=12,20.7 \%)$, pregnancy wish/confirmed pregnancy $(n=8,13.8 \%)$, patient's decision $(n=4,6.9 \%)$, newly diagnosed rheumatologic disease $(n=1,1.7 \%)$, and unknown reason $(n=1,1.7 \%)$. Table 1 summarizes the baseline characteristics of the study population.

Most patients continued with an immunomodulatory treatment after fingolimod stop (figure 1).

\section{Lymphocyte counts after fingolimod discontinuation}

Prefingolimod lymphocyte count (median 28 days [0-152] before fingolimod start) was available in 53 patients. Three of these patients had lymphopenia (each with grade 1, grade 2, and grade 3, respectively): 2 of them were on interferon beta$1 \mathrm{~b}$ treatment, whereas 1 patient had received mitoxantrone until 4 years before sampling. Five patients on natalizumab showed lymphocyte counts above the upper limit of normal $\left(>3.3 \times 10^{9} / \mathrm{L}\right)$.

To evaluate the grade of lymphopenia under fingolimod, the last available lymphocyte count before therapy cessation was used. We analyzed lymphocyte, leukocyte, and granulocyte counts at the time point of switching to a follow-up treatment (median 1 day [0-80]), and 3 (median 81 days [28-145]), 6 (median 185 days [112-272]), and 12 months (median 369 days [250-477]) after therapy cessation. Lymphopenia because of an immunomodulatory regimen with expected reduction of lymphocyte count $<0.5 \times 10^{9} / \mathrm{L}$ (fingolimod and alemtuzumab) was not included in the analysis. With these criteria, blood tests of 56 patients at fingolimod stop, 29 at therapy switch, 47 for the 3 months, 46 for the 6 months, and 49 patients for the 12 months time point were analyzed.

Fingolimod resulted in a drop of lymphocyte count by $76 \%$ compared with pretreatment; however, no leukopenia or neutropenia was detected. Twelve months after fingolimod stop, lymphocyte counts were normalized in $77.6 \%$ of the patients and did not reach $80 \%$ of the baseline value in 54\% (after excluding those with baseline lymphocyte counts $>3.3 \times 10^{9} / \mathrm{L}$ because of preceding natalizumab) (figure 2, A). One year after fingolimod cessation, 11 patients were still lymphopenic (22\%) (figure 2, B). Prolonged lymphopenia was mostly grade 2 (Supplemental figure 2, links.lww.com/NXI/A306).

\section{Main characteristics of patients with prolonged lymphopenia}

Table 1 shows the characteristics of the 11 patients with prolonged lymphopenia compared with patients with normalized lymphocyte counts. Lymphocyte count before fingolimod start, at fingolimod stop, pretreatment with mitoxantrone, and a following anti CD-20 depleting therapy were associated with prolonged lymphopenia. The association of rituximab and prolonged lymphopenia persisted when adjusting for covariates (table 2).

Glucocorticoid treatment within 1 year after fingolimod cessation showed no association with prolonged lymphopenia. One patient in the lymphopenic group had sepsis because of an infected toe within 1 year after fingolimod stop without any further infections in this patient group.

\section{Characteristics of patients with subsequent rituximab treatment}

Eight of 17 patients (47\%) who were switched to rituximab showed prolonged lymphopenia. Those patients who stayed 
Table 2 Association between prolonged lymphopenia and predefined predictors

\begin{tabular}{lll}
\hline Variable & OR & 95\% Cl \\
\hline Age at fingolimod start & 1.01 & $0.96-1.07$ \\
\hline EDSS at fingolimod start & 1.05 & $0.70-1.55$ \\
\hline Disease duration at fingolimod start & 0.97 & $0.88-1.06$ \\
\hline Fingolimod treatment duration & 1.00 & $1.00-1.00$ \\
\hline No. of pretreatments & 1.28 & $0.60-2.72$ \\
\hline Previous mitoxantrone & 13.87 & $1.56-301.85$ \\
\hline Follow-up with rituximab & 16.87 & $3.53-126.71$ \\
\hline Lymphocytes before fingolimod & 0.20 & $0.03-0.68$ \\
\hline Lymphocytes at fingolimod stop & 0.00 & $0.00-0.02$ \\
\hline
\end{tabular}

Abbreviations: $\mathrm{Cl}$ = confidence interval; EDSS = Expanded Disability Status Scale; OR = odds ratio.

$\mathrm{OR}$ and $95 \% \mathrm{Cl}$ are based on a simple linear model.

lymphopenic on rituximab had a lower EDSS score at the fingolimod start (median 2.5 vs 4.0), and a lower lymphocyte count at baseline (median 1.3 vs $1.7 \times 10^{9} / \mathrm{L}$ ) and at therapy switch (median 0.62 vs $1.02 \times 10^{9} / \mathrm{L}$ ) compared with those without prolonged lymphopenia under rituximab. All patients pretreated with mitoxantrone belonged to the lymphopenic group.

\section{Discussion}

Under standardized conditions of clinical trials, prolonged lymphocyte recovery after fingolimod cessation was considered as an exception. ${ }^{3}$ However, peripheral lymphocyte reconstitution might be prolonged after therapy withdrawal despite preserved lymph node architecture. ${ }^{6,7}$ Our real-life analysis shows that lymphocytes recover in most patients without-in average-further increase from the levels attained at 3 months postcessation. However, fingolimod-induced lymphopenia persists in $22 \%$ of patients for at least up to 1 year after fingolimod stop. Limitations of our analysis are the low patient number and the lack of a standardized follow-up.

Patients with lower lymphocyte counts before fingolimod, under treatment, and at therapy switch, pretreated with mitoxantrone, and on rituximab follow-up treatment seem to be at a higher risk for prolonged lymphopenia. Because rituximab primarily affects B cells and B cells constitute only a minor percentage of lymphocytes, it is conceivable that a prolonged lymphopenia is at least partly caused by the pretreatment with fingolimod.

The described characteristics may have not shown up in clinical trials because patients were treated for a shorter period, previous mitoxantrone treatment was an exclusion criterion, and the effect of a follow-up treatment was not analyzed. It is therefore of utmost importance to evaluate the safety and pharmacodynamics of fingolimod in the context of the treatment history and the future treatments of the patient.

\section{Acknowledgment}

The authors acknowledge support for the statistical analysis from Sabine Schädelin, MSc, from the Clinical Trial Unit, University of Basel.

\section{Study funding}

No targeted funding reported.

\section{Disclosure}

S. Nagy and J. Kuhle have no disclosures related to the manuscript. T. Derfuss serves on scientific advisory boards for Novartis, Merck, Biogen, Genzyme, GeNeuro, Mitsubishi Tanabe Pharma, Roche, and Celgene; has received funding for travel and/or speaker honoraria from Biogen, Genzyme, Novartis, Merck, and Roche; and received research support from Biogen, Novartis, Roche, the European Union, the Swiss National Science Foundation, and the Swiss MS Society. Go to Neurology.org/NN for full disclosures.

\section{Publication history}

Received by Neurology: Neuroimmunology \& Neuroinflammation July 10, 2019. Accepted in final form July 15, 2020.

Appendix Authors

\begin{tabular}{lll}
\hline Name & Location & Contribution \\
\hline $\begin{array}{l}\text { Sara Nagy, } \\
\text { MD, MSc }\end{array}$ & $\begin{array}{l}\text { University Hospital of } \\
\text { Basel, University of Basel, } \\
\text { Switzerland }\end{array}$ & $\begin{array}{l}\text { Analyzed the data and drafted } \\
\text { the manuscript for intellectual } \\
\text { content }\end{array}$ \\
\hline $\begin{array}{l}\text { Jens } \\
\text { Kuhle, } \\
\text { MD, Prof. }\end{array}$ & $\begin{array}{l}\text { University Hospital of } \\
\text { Basel, University of Basel, } \\
\text { Switzerland }\end{array}$ & $\begin{array}{l}\text { Interpreted the data and } \\
\text { revised the manuscript for } \\
\text { intellectual content }\end{array}$ \\
\hline $\begin{array}{l}\text { Tobias } \\
\text { Derfuss, } \\
\text { MD, Prof. }\end{array}$ & $\begin{array}{l}\text { University Hospital of } \\
\text { Basel, University of Basel, } \\
\text { Switzerland }\end{array}$ & $\begin{array}{l}\text { Interpreted the data and } \\
\text { revised the manuscript for } \\
\text { intellectual content }\end{array}$ \\
\hline
\end{tabular}




\section{References}

1. Cohen JA, Khatri B, Barkhof F, et al; TRANSFORMS (Trial Assessing injectable interferoN vS. FTY720 Oral in RRMS) Study Group. Long-term (up to 4.5 years) treatment with fingolimod in multiple sclerosis: results from the extension of the randomised TRANSFORMS study. J Neurol Neurosurg Psychiatry 2016;87:468-475.

2. Francis G, Kappos L, O'Connor P, et al. Temporal profile of lymphocyte counts and relationship with infections with fingolimod therapy. Mult Scler J 2014;20:471-480.

3. Duquette P, Yeung M, Mouallif S, Nakhaipour HR, Haddad P, Schecter R. A retrospective claims analysis: compliance and discontinuation rates among Canadian patients with multiple sclerosis treated with disease-modifying therapies. PLoS One 2019;14:e0210417.
4. Hatcher SE, Waubant E, Nourbakhsh B, Crabtree-Hartman E, Graves JS. Rebound syndrome in patients with multiple sclerosis after cessation of fingolimod treatment. JAMA Neurol 2016;73:790-794.

5. Disanto G, Benkert P, Lorscheider J, et al; SMSC Scientific Board. The Swiss Multiple Sclerosis Cohort-Study (SMSC): a prospective Swiss wide investigation of key phases in disease evolution and new treatment options. PLoS One 2016;11:e152347.

6. Johnson TA, Shames I, Keezer M, et al. Reconstitution of circulating lymphocyte counts in FTY720-treated MS patients. Clin Immunol 2010;137:15-20.

7. Ghadiri M, Fitz-Gerald L, Rezk A, et al. Reconstitution of the peripheral immune repertoire following withdrawal of fingolimod. Mult Scler 2017;23:1225-1232. 


\section{Neurology \\ Neuroimmunology \& Neuroinflammation}

Lymphocyte recovery after fingolimod discontinuation in patients with MS

Sara Nagy, Jens Kuhle and Tobias Derfuss

Neurol Neuroimmunol Neuroinflamm 2020;7;

DOI 10.1212/NXI.0000000000000874

This information is current as of August 14, 2020

\section{Updated Information \& Services}

References

Citations

Subspecialty Collections

Permissions \& Licensing

Reprints including high resolution figures, can be found at: http://nn.neurology.org/content/7/6/e874.full.html

This article cites 7 articles, 1 of which you can access for free at: http://nn.neurology.org/content/7/6/e874.full.html\#\#ref-list-1

This article has been cited by 3 HighWire-hosted articles: http://nn.neurology.org/content/7/6/e874.full.html\#\#otherarticles

This article, along with others on similar topics, appears in the following collection(s):

All Clinical Neurology

http://nn.neurology.org//cgi/collection/all_clinical_neurology All Demyelinating disease (CNS)

http://nn.neurology.org//cgi/collection/all_demyelinating_disease_cns Multiple sclerosis

http://nn.neurology.org//cgi/collection/multiple_sclerosis

Information about reproducing this article in parts (figures,tables) or in its entirety can be found online at:

http://nn.neurology.org/misc/about.xhtml\#permissions

Information about ordering reprints can be found online: http://nn.neurology.org/misc/addir.xhtml\#reprintsus

Neurol Neuroimmunol Neuroinflamm is an official journal of the American Academy of Neurology.

Published since April 2014, it is an open-access, online-only, continuous publication journal. Copyright

Copyright (C) 2020 The Author(s). Published by Wolters Kluwer Health, Inc. on behalf of the American

Academy of Neurology.. All rights reserved. Online ISSN: 2332-7812.

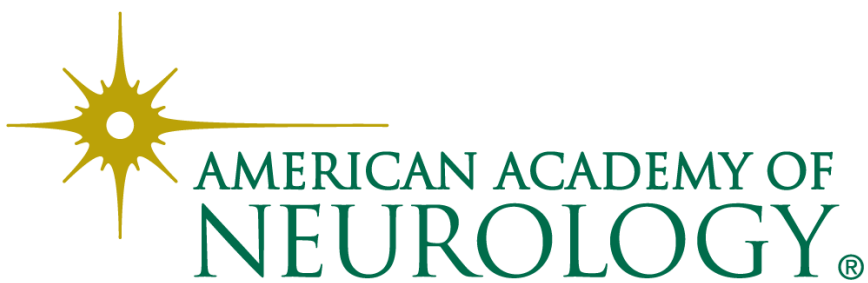

